\title{
QUIROGA PARA CRIANÇAS: ENSINANDO ESPANHOL ATRAVÉS DA LEITURA DO CONTO
}

\author{
Maria José da Silva Leandro* \\ Maria Luiza Teixeira Batista**
}

\begin{abstract}
Resumo: Este trabalho tem como objetivo refletir sobre a inclusão e a valorização da literatura na aula de espanhol como língua estrangeira, principalmente em turmas do Ensino Fundamental I. Durante o segundo semestre do ano de 2012, realizamos uma pesquisa com alunos do $2^{\circ}$ ano do Ensino Fundamental I em uma escola na cidade de João Pessoa, Paraíba. Para tornar possível nossa pesquisa, utilizamos como base teórica alguns escritores, tais como Cândido (2004), Zilberman (2008), Cuesta (2006), Cosson (2007), Eres Fernández e Flávian (2008). Esses escritores discutem sobre a importância da leitura literária na sala de aula e trazem algumas sugestões de atividades com textos literários, que podem ser desenvolvidas com os alunos.
\end{abstract}

Palavras-chave: Literatura. Língua espanhola. Leitura. Ensino-aprendizagem.

\begin{abstract}
This paper aims to reflect on the inclusion and on the appreciation of literature in Spanish classes as a foreign language, especially in Elementary School. In the second term of 2012, we conducted a survey with students attending the 2nd year of an Elementary School in the city of João Pessoa, Paraíba. To make our research possible, we used as a theoretical basis some authors such as Candido (2004), Zilberman (2008), Cuesta (2006), Cosson (2007), Eres Fernández and Flávian (2008). These authors discuss the importance of literary reading in the classroom and provide some suggestions for activities with literary texts, which can be performed with the students.
\end{abstract}

Keywords: Literature. Spanish language. Reading. Teaching and learning.

\section{Introdução}

Este trabalho tem como objetivo principal apresentar uma reflexão sobre a inclusão do texto literário na sala de aula de língua espanhola e, ao mesmo tempo, relatar uma experiência realizada com um grupo de alunos do segundo ano do ensino fundamental I. ${ }^{1}$ Nessa experiência, decidimos trabalhar com a leitura de contos e, para tanto, utilizamos como base teórica críticos e autores, como Antonio Cândido (2004), Zilberman (2008), Cuesta (2006), Cosson (2007), Eres Fernández e Flávian (2008). Eles discutem sobre a importância da leitura literária na sala de aula e trazem algumas sugestões de atividades com textos literários, que podem ser desenvolvidas com os alunos. Acreditamos que as vantagens que a literatura oferece vão além da aprendizagem do vocabulário, de conteúdos gramaticais e linguísticos, como argumenta o escritor Antonio Cândido ao atribuir à literatura um papel humanizador. Além disso, constatamos que o ato de ler textos literários contribui para o aprendizado dos alunos, porque a literatura permite uma apreciação intensa de uma língua estrangeira na fala e na escrita.

\footnotetext{
* Graduada em Letras (Espanhol) pela Universidade Federal da Paraíba e foi orientanda da professora Dra. Maria Luiza Teixeira Batista. Endereço eletrônico: mazeleandro@gmail.com

** Doutora em Letras e professora de Literatura Hispano-Americana no Curso de Licenciatura em Letras (Espanhol) da Universidade Federal da Paraíba. Endereço eletrônico: luizabatista.ufpb@gmail.com

${ }^{1}$ A pesquisa aqui relatada foi realizada no âmbito do projeto Prolicen intitulado "Ler pode ser divertido: a leitura literária na sala de aula de língua espanhola" e resultou no trabalho de final de curso de Maria José da Silva Leandro.
} 


\section{Literatura na aula de língua espanhola}

Como dissemos, para realizar essa experiência, decidimos trabalhar com a leitura de contos, escolhemos então o conto Las medias de los flamencos, do escritor Horacio Quiroga. Esse escritor nasceu no Uruguai, mas passou a maior parte na sua vida na Argentina, mais especificamente em uma região de selva próximo da fronteira com o Brasil. Nesse lugar, ambientou quase todas suas histórias, que, por sua vez, estão ligadas a sua vida pessoal, marcada por muitas tragédias. Talvez seja por isso que Quiroga é citado pelos críticos como o escritor da selva e da morte, pois na maioria dos seus contos a morte está presente, como esteve presente na sua vida. Porém, neste trabalho, buscamos, como disse María Luisa Cresta de Leguizamón, a outra face do escritor, um escritor que escreveu contos infantis, como os oito relatos do livro Cuentos de la selva (1918) no qual se encontra o conto aqui citado.

A escolha do gênero conto como matéria principal dessa experiência se explica porque ele é narrativo e breve, permitindo que o professor explore melhor o tempo da aula, que tem a duração de 45 minutos. Ademais, reiterando o que dizem Eres Fernández e Flavián (2008, p. 22), o texto literário traz consigo temas diversificados, podendo ser trabalhado em diferentes contextos: o "texto literario permite que se aborden de manera contextualizada temas muy variados", e esses temas variados enriquecem a aprendizagem dos alunos. Além disso, algumas características da obra de Quiroga também nos incentivaram a trabalhar com seus contos. A primeira delas é a maneira como o escritor aborda assuntos relacionados às questões humanas, sociais e culturais. Isso nos ajudou a discutir temas presentes no cotidiano dos alunos e aproximá-los do objeto de estudo, no nosso caso, a língua espanhola. Em segundo lugar, seus textos apresentam uma linguagem simples e acessível, que convida o leitor a aproximar-se e às vezes identificar-se com a narrativa.

Como já mencionamos a atividade com a leitura de contos foi realizada em uma turma do $2^{\circ}$ ano do Ensino Fundamental I em uma escola da nossa região. A turma escolhida era composta por sete alunos, na faixa etária de seis e sete anos. Esse trabalho foi realizado entre agosto e dezembro, mas nossos dados foram colhidos em outubro, porque os alunos necessitavam de algum tempo para conhecer um pouco a língua espanhola e se adaptar a essa nova disciplina, já que era a primeira vez que estudavam uma língua estrangeira. É importante informar que, antes da realização da atividade aqui descrita, já havíamos desenvolvido outros exercícios com poesias, músicas e videoaulas, uma vez que a ideia era trabalhar diferentes textos para tornar as aulas mais dinâmicas e, com isso, facilitar a aprendizagem dos alunos.

\section{0 papel da literatura na sala de aula}

Nos últimos anos, foram realizadas muitas investigações, como as que citamos neste trabalho, sobre a importância da literatura para a aprendizagem dos alunos. Algumas delas nos fazem refletir sobre a forma como a literatura atua no meio social e na sala de aula, uma vez que, como arte, é um direito e necessidade de todos, como nos afirma Candido (2004, p. 191). $\mathrm{O}$ contato com a literatura enriquece a aprendizagem do homem como indivíduo, pois ela se manifesta em tudo aquilo que pode ser tocado, visto ou imaginado. Tudo isso se torna possível porque a literatura "nos torna mais compreensivos e abertos para a natureza, a sociedade, o semelhante" (2004, p. 182). Candido ainda acrescenta que a literatura tem uma natureza complexa e contraditória, mas é essa contradição que a torna humanizadora e anima o cidadão a viver, porque exerce um papel organizador que ajuda o ser humano a ordenar suas ideias e sentimentos, além de oferecer ao cidadão uma postura crítica sobre o mundo, fazendo-o refletir sobre suas opiniões e sobre a maneira de conviver com seu semelhante.

Corroborando com o que diz Candido, Cosson (2007) defende que, na sala de aula, 
"a literatura serve tanto para ensinar a ler e a escrever quanto para formar culturalmente o indivíduo" (2007, p. 20). Dessa maneira, trabalhar com o texto literário na sala de aula pode trazer resultados positivos. Entretanto, para isso, segundo Fernández e Flavián, o professor deverá planejar bem as aulas, pensando em atividades que tenham nexo, ou seja, início, meio e fim, ou pré-leitura, leitura e pós-leitura. Outra peça importante nesse quebra-cabeças é o efeito duplo: afetivo e crítico (ZILBERMAN, 2008, p. 53). Para Zilberman, o envolvimento afetivo funciona como facilitador no processo de aprendizagem.

Os autores aqui citados foram fundamentais para o desenvolvimento deste trabalho, uma vez que nos ajudaram a desenvolver atividades com literatura, enfocando elementos capazes de atravessar o campo lexical e sintático da língua para alcançar o campo da aprendizagem, dos sentidos e da afetividade.

Sabemos que, nas escolas, os alunos têm poucas aulas de língua estrangeira durante a semana e o tempo determinado para cada aula é considerado curto; mesmo assim, é possível trabalhar com literatura. Além disso, temos os documentos oficiais da educação brasileira, os Parâmetros Curriculares para os Ensinos Fundamental e Médio, que nos apoiam nesse trabalho. Então, investigamos como a literatura é abordada nesses documentos. Nos Parâmetros Curriculares para o Ensino Médio, a literatura é usada como "contextualização de conteúdos de ensino" (2000, p. 80). Os alunos irão compreender os conteúdos por meio de atividades, e essas atividades podem ser desenvolvidas através dos textos literários.

Como está escrito nos Parâmetros Curriculares para o Ensino Fundamental (PCNEF), a aula de língua estrangeira está voltada para o uso da linguagem em quatro competências comunicativas básicas: compreensão oral e escrita e produção oral e escrita, ou seja, ler, entender, escrever e falar (1998). Além disso, observamos que, nesses documentos, dá-se uma maior importância à leitura, uma vez que esta "representa um apoio importante para a compreensão dos significados, funcionamento e uso da língua estrangeira" (p. 55). Acrescenta-se que o aluno precisa saber ler e identificar os diferentes gêneros textuais, como também a sua organização. A partir disso, entendemos a leitura em um sentido abrangente e que ler textos literários faz parte desse contexto.

É importante ressaltar que a proposta predominante nesses documentos é desenvolver ou formar o cidadão, objetivo dirigido ao ensino de língua estrangeira, porque enfoca a inclusão social vinculada ao conhecimento de uma segunda língua. Observamos que os documentos dão pouca atenção à leitura literária nas aulas de idiomas, porém acreditamos que esse tipo de leitura exerce um papel fundamental na formação do cidadão, uma vez que lhe dá a oportunidade de refletir sobre seu cotidiano e suas escolhas, tornando-o mais crítico e aberto a novas opiniões. Para isso, o professor deve estimular os alunos, buscando desenvolver determinadas capacidades e competências, incentivando sua criatividade, liberdade de expressão, percepção e reflexão.

Segundo Cosson (2007), para que o texto seja explorado e trabalhado com os alunos, é necessário que o docente faça as perguntas certas, não bastando elaborar questões como: quem escreveu o texto? Em que ano foi escrito? Quem são os personagens que participam da história? Essas questões também são importantes para a compreensão do texto, mas é preciso analisar o texto de maneira mais profunda.

Segundo Fernández e Flavián (2008), as atividades feitas em sala de aula deverão ser agradáveis e apresentar uma lógica na preparação e realização; além disso, para trabalhar os textos literários em sala de aula, o professor necessitará de tempo, mas como o tempo destinado à língua estrangeira é pouco, as autoras optaram por dividir a atividade em etapas. Elas elaboraram um esquema de preparação das atividades repartido em três momentos: préleitura, leitura e pós-leitura. Afirmam Fernández e Flavián (2008): 
[...] no se trata simplemente de decirles a los estudiantes que lo lean y lo discutan, pues seguramente los resultados no serán los esperados o deseados. Por lo tanto, hay que cumplir una serie de etapas para garantizar no sólo que se lean, sino que esa lectura resulte agradable y provechosa. En ese sentido, conviene establecer con claridad actividades de prelectura, de lectura y de poslectura, como se hace con cualquier texto que se lleve a clase. (FERNÁNDEZ E FLAVIÁN, 2008, p. 22).

O professor deverá planejar com cuidado cada etapa. A pré-leitura seria uma introdução do assunto; a leitura seria a execução da atividade; e a pós-leitura seria a conclusão da atividade, o fechamento do círculo. Porém, para Cuesta (2006), o profissional poderá ir mais além, poderá elaborar perguntas que estimulem o aluno a pensar e entender os vários sentidos do texto. Além disso, o professor poderá trabalhar com instrumentos pedagógicos como imagens ou marionetes, por exemplo. Esses instrumentos ajudariam o professor a promover aulas mais dinâmicas e seriam um meio para que os alunos se envolvessem com o texto, fazendo da leitura uma ponte para a aprendizagem.

Segundo Cuesta (2006), no momento da leitura, o aluno deve explorar os sentidos do texto e compreendê-los. Não basta ler o texto, é preciso entendê-lo, por isso, orientar e ajudar o aluno a compreender o que foi lido dependerá da maneira como o professor abordará a leitura na sala de aula. Para tanto, ele deverá elaborar perguntas que possam levá-los a refletir sobre a leitura. O professor deverá também permitir que os alunos expressem o que pensam, dando a oportunidade de "compartir la lectura, no en un silencio solemne, sino discutir sentidos" (CUESTA, 2006, p. 27). Esses sentidos, por sua vez, estão relacionados às diversas formas de ler e interpretar o texto.

Como disse Zilberman (2008), a literatura tem a capacidade de tocar no mais profundo da afetividade humana. $O$ afetivo seria a ligação entre o leitor e texto, a fantasia e o real compartilhando o mesmo espaço. O texto provoca a imaginação do leitor, levando a um "posicionamento intelectual, uma vez que o mundo representado no texto, mesmo afastado no tempo ou diferenciado enquanto invenção, produz uma modalidade de reconhecimento em quem lê" (ZILBERMAN, 2008, p. 53). Para a escritora,

[...] a leitura do texto literário constitui uma atividade sintetizadora, permitindo ao indivíduo penetrar o âmbito da alteridade, sem perder de vista sua subjetividade e história. O leitor não esquece suas próprias dimensões, mas expande as fronteiras do conhecido, que absorve através da imaginação e decifra por meio do intelecto. (ZILBERMAN, 2008, p. 53).

O trabalho em conjunto entre o professor e alunos, conduzirá a uma troca de conhecimentos, levando posteriormente a uma sociedade com mais apreço, porque, segundo Zilberman (p. 57): "Etimologicamente, educar é extrair, levar avante, conduzir para fora e para frente". Conduzir para frente a aprendizagem é tentar encontrar a melhor forma de ensinar os alunos. Foi o que tentamos realizar com a aplicação do conto na sala de aula de espanhol para crianças. Essa é a experiência que relataremos a seguir.

\section{Quiroga para crianças}

Nesta seção do nosso texto, apresentaremos o processo de preparação e desenvolvimento da atividade realizada com o conto Las medias de los flamencos de Horacio Quiroga em uma turma do segundo ano do Ensino Fundamental I. 
Por ser um grupo de crianças que estavam iniciando os estudos da língua espanhola, foi necessário estabelecer alguns critérios na hora da elaboração da atividade. Entre estes citamos: 1) não sermos repetitivos na execução da atividade e calcular o tempo de cada prática, para evitar que os alunos se dispersassem; 2) realizar uma atividade atrativa para as crianças, utilizando o recurso do teatrinho de marionetes para narrar a história; 3 ) trabalhar, no momento da escrita, com uma atividade que pudesse atrair a atenção das crianças.

Além disso, tentamos elaborar uma atividade com nexo: o trabalho foi iniciado com uma pré-leitura, seguido de uma leitura e, posteriormente, de uma pós-leitura, essas três etapas são apresentadas por Fernández e Flavián (2008), como descrevemos anteriormente. Essas duas autoras defendem a ideia de que a atividade não pode ser realizada ao acaso ou sem coerência, mas deve seguir uma lógica que inclui: a escolha do texto, a elaboração e aplicação da atividade, e também o contexto no qual os alunos estão inseridos. Assim, planejamos a atividade com o conto Las medias de los flamencos, considerando a pré-leitura, leitura e pós-leitura.

A atividade foi elaborada para ser trabalhada em duas aulas, com duração de 45 minutos cada uma. Nossos objetivos eram: 1) apresentar o vocabulário que os alunos ainda não conheciam; 2) introduzir o pronome interrogativo quién, na pergunta: Quién es?; 3) apresentar o verbo ser: soy/somos; 4) e explorar os sentidos presentes no conto.

$\mathrm{Na}$ primeira aula, realizamos a etapa da pré-leitura. Começamos explicando aos alunos os significados das palavras referentes ao vocabulário presente no conto, tais como: víboras de coral, loro, sapo, flamenco, yacaré, pez (peces), mono, lechuza e tatu. Também apresentamos os verbos principais: invitar, bailar, adornar, gustar, volar, mirar, cansar e caer; e os significados das seguintes palavras: tristeza, alegria, inteligente e loco. Nesse momento da atividade, instigamos os alunos a compreender o significado de cada palavra através de imagens. Vale ressaltar que essa etapa foi necessária para que os alunos pudessem compreender o conto que seria lido em seguida.

Acreditamos que, com o entendimento do vocabulário presente no conto, os alunos teriam mais facilidade para compreender e entender a narrativa na hora da leitura, por isso, trabalhamos primeiro a parte lexical, pois concordamos com Fernández e Flavián (2008, p. 25) quando afirmam que é importante "llamar la atención sobre el léxico y estruturas más relevantes" antes de proceder à etapa da leitura. Aprender o vocabulário e a estrutura das frases em espanhol também ajudará os alunos a compreender que a língua que eles estão aprendendo é outro idioma, com estrutura e vocabulário diferentes da sua língua materna.

$\mathrm{Na}$ etapa seguinte, realizamos uma atividade lúdica com o propósito de trabalhar a estrutura: Quién es? e soy/somos. Para trabalhar a estrutura Quién es?, partimos do conhecimento dos alunos, indagando a forma como os alunos perguntariam sobre a identidade de uma pessoa. Logo depois, a turma foi dividida em dois grupos, um deles permaneceu na sala e o outro se retirou. Cada aluno que estava fora da sala recebeu uma figura contendo a imagem de algum dos personagens do conto. Esses alunos batiam na porta, e os que estavam dentro da sala perguntavam em espanhol: Quién es? O outro grupo respondia de acordo com a figura que possuía: Yo soy... (o aluno dizia o nome do animal da sua figura) ou Somos... (com o nome dos animais da sua figura).

Com essa atividade, notamos que houve interação entre os alunos, uma vez que ficavam curiosos em fazer a pergunta Quién es?, para descobrir quem era cada animal, e comentavam entre eles sobre o personagem de cada um. Também observamos que os alunos demonstraram confiança em realizar a atividade, pois não se inibiam em falar palavras em um idioma estrangeiro. Isso se deve ao fato de considerarem tal atividade uma brincadeira e estarem, portanto, se divertindo, além de aprendendo. Também percebemos que o lúdico contribuiu para uma melhor interação entre os alunos, deixando todos à vontade para participar. De acordo com os autores Salomão, Martini e Jordão (2007, p. 08), ensinar 
"utilizando meios lúdicos cria ambientes gratificantes e atraentes servindo como estímulo para o desenvolvimento integral da criança."

Como já foi mencionado, essa atividade tinha o objetivo de fazer com que os alunos aprendessem a estrutura acima citada, além de incentivar o trabalho em grupo. Esse tipo de trabalho ajuda o aluno a interagir com seu colega, compartilhando suas dúvidas, ideias e aprendendo com o outro. Segundo Sin Maciel (2008, p. 21), "para la interacción es preferible que el aprendizaje sea en pequeños grupos, en los que se intercambien informaciones" ou seja, o trabalho em grupo é importante para a aprendizagem dos alunos, porque podem compartilhar seus conhecimentos. Finalmente, encerramos a etapa da pré-leitura, que teve a duração de 45 minutos. As duas etapas, leitura e pós-leitura, ficaram para a semana seguinte.

$\mathrm{Na}$ segunda aula, retomamos o assunto que tinha sido trabalhado na aula anterior e iniciamos a etapa seguinte, a da leitura. Lemos o conto para os alunos, porque eles ainda não sabiam ler com fluência em espanhol, mas conseguiam entender quando o texto era lido em voz alta. É importante destacar que essa leitura foi realizada com o apoio de um teatrinho de marionetes.

Decidimos usar o teatrinho de marionetes porque acreditamos ser um recurso útil para ser usado em uma sala de aula de crianças. Esse teatrinho era uma estrutura simples de papelão em forma de caixa, com uma abertura no centro, onde os personagens "atuavam". Nele, desenhamos figuras que representavam a selva, como: árvores, rios, pássaros, etc. Os personagens que aparecem na história foram desenhados e recortados em cartolina em forma de pequenas marionetes para que pudéssemos manipulá-los enquanto líamos o conto.

Essa forma de ler e apresentar o conto foi importante, porque queríamos que as crianças compreendessem o que estava sendo trabalhado e que entendessem a história que estava sendo contada. E teve como objetivo trabalhar a compreensão auditiva dos alunos, pois, de acordo com Sin Maciel (2008), a leitura em voz alta ajuda o aluno a desenvolver o hábito de ouvir em espanhol, pois "el hecho de leer o escuchar el cuento, aclarar las dudas de vocabulario y de comprensión, produce un enlace a otros conocimientos de mundo" (p. 93).

Em seguida, na etapa da pós-leitura, os alunos recontaram o conto. Essa tarefa tinha o objetivo de observar se os alunos haviam conseguido compreender o que havia sido narrado. Percebemos que a maioria dos alunos não teve dificuldade em interpretar e compreender a história. Além disso, conseguiram identificar alguns assuntos presentes na história, como a mentira, a inveja e o castigo.

Ainda como atividade de pós-leitura, os alunos realizaram uma tarefa que teve como finalidade trabalhar a expressão escrita, fixando o assunto abordado. Para tanto, elaboramos uma atividade com as imagens do livro As meias dos flamingos (2008), que é uma tradução ao português do conto de Quiroga feito por Andrea Ponte e ilustrado por Fê. É importante informar que não usamos a tradução, mas a ilustração apresentada na Fig. 1. Escolhemos essa parte do texto porque, além de colorida, a imagem continha a maioria dos animais que protagonizam o conto. Essa página foi escaneada e impressa para cada um dos alunos, que tinham como tarefa escrever o nome dos animais ali representados. 


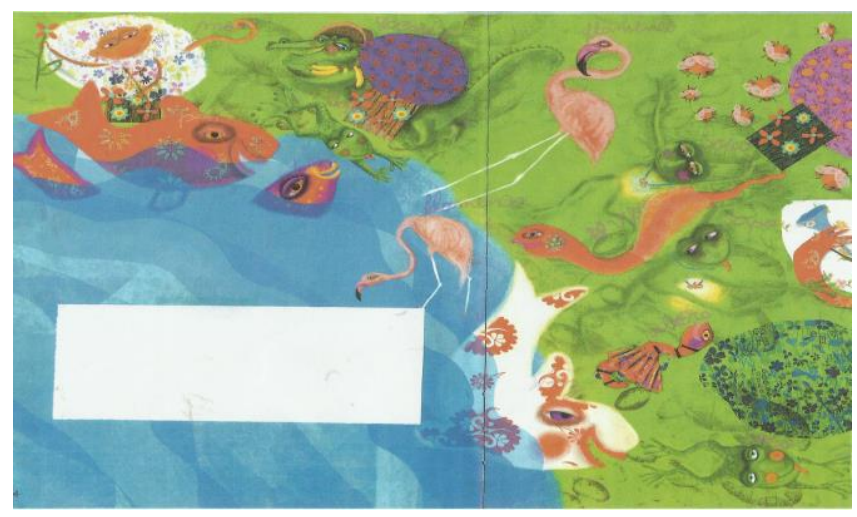

Figura 1 - Ilustração da atividade escrita

Reprodução da ilustração do livro As meias dos flamingos (2008)

Observamos que a atividade escrita foi produtiva, porque quase todos os alunos conseguiram escrever os nomes dos animais em espanhol. Observamos também que no momento da leitura do conto, os alunos ficaram em total silêncio, prestando atenção à história que estava sendo narrada. Por causa disso, no momento da pós-leitura, os alunos não encontraram dificuldades em recontar o conto, nem em realizar a tarefa descrita acima. Acreditamos que essa atividade teve um resultado satisfatório, porque percebemos que houve uma boa interação entre os alunos que, por sua vez, proporcionou um clima agradável na sala de aula. Além disso, percebemos que eles conseguiram realizar todas as etapas da atividade sem muitas dificuldades.

\section{Considerações finais}

Trabalhar textos literários em sala de aula, tendo como público-alvo crianças, foi desafiador, por esse motivo, o mínimo que esperávamos dos alunos era que eles, além de compreender o sentido da narrativa, também entendessem o vocabulário, a estrutura Quién es? e o verbo ser na primeira pessoa do singular e plural: soy/somos. Notamos que os alunos foram além desses limites, ultrapassando o campo linguístico e gramatical. Eles apresentaram reflexões acerca dos temas trabalhados e demonstraram satisfação por estar escrevendo algumas palavras e frases em espanhol. A maioria deles não hesitou em participar das atividades realizadas; pelo contrário, demonstravam motivação em todas as etapas do trabalho.

Para concluir nosso texto, falta dizer que a leitura literária em língua estrangeira é, sem dúvida, uma ferramenta imprescindível no processo de ensino-aprendizagem por reunir as mais completas experiências de vida e de conhecimento de mundo. Ela é um bem indispensável, um patrimônio, um direito e, por isso, não deve ser excluída das práticas de sala de aula de língua materna e muito menos de idiomas. 


\section{Referências}

BRASIL. Parâmetros Curriculares Nacionais: Ensino Médio. Brasília: MEC/SEMT, 2000.

Parâmetros curriculares nacionais: terceiro e quarto ciclos do Ensino Fundamental. Brasília: MEC/SEF, 1998.

CANDIDO, A. O direito à literatura. In: Vários escritos. 4 ed. São Paulo: Duas Cidades, 2004, p. 169-191.

COSSON, R. Letramento literário: teoria e prática. 2 ed. São Paulo: Contexto, 2007.

CRESTA DE LEGUIZAMÓN, M. L. Horacio Quiroga, escritor para niños. Disponível em: $<$ http://www.cervantesvirtual.com/obra-visor/boletin-asociacion-espanola-de-amigos-delibby--6/html/025d8546-82b2-11df-acc7-002185ce6064_3.html>. Acesso: 15 out. 2013.

CUESTA, C. Discutir sentidos: la lectura literária em la escuela. Buenos Aires: Libros Del Zorzal, 2006.

ERES FERNÁNDEZ, I. G.; FLAVIÁN, E. Un cuento aquí, otro más allá. In: XVI Seminario de dificultades específicas para la enseñanza del español a luso hablantes: "Cuando despertó, el cuento todavía estaba allí". Cuentos y relatos en el aula de ELE. São Paulo: Educacion.es, 2008, p. 19-29.

QUIROGA, H. Cuentos Completos. Buenos Aires: Fondo de Cultura Económica, 1996.

. As meias dos flamingos. Tradução e adaptação de Andrea Ponte e ilustrações de Fê. São Paulo: Larousse do Brasil, 2008.

SIN MARCIEL, A. El encanto del cuento en la clase de ELE: comprensión, interacción y contexto. In: XVI Seminario de dificultades específicas para la enseñanza del español a luso hablantes: "Cuando despertó, el cuento todavía estaba alli". Cuentos y relatos en el aula de ELE. São Paulo: Educaciones, 2008, p. 89-94.

SAlOMÃO, H. A. S.; MARTINI, M.; JORDÃO, A. P. M. A importância do lúdico na educação infantil: enfocando a brincadeira e as situações de ensino não direcionado. Disponível em: 〈http://www.psicologia.pt/artigos/textos/A0358.pdf>. Acesso em: 01 out. 2014.

ZILBERMAN, R. Literatura, escola e leitura. In: SANTOS, J. F. dos; OLIVEIRA, L. E. (Org.). Literatura e ensino. Maceió: Edufal, 2008, p. 45-60.

Recebido em: dezembro de 2015.

Aprovado em: março 2016. 